\title{
Gallbladder Adenocarcinoma, Biliary Type
}

National Cancer Institute

\section{Source}

National Cancer Institute. Gallbladder Adenocarcinoma, Biliary Type. NCI Thesaurus.

Code C96915.

A well or moderately differentiated adenocarcinoma that arises from the gallbladder. It is the most common type of gallbladder carcinoma and is characterized by the presence of malignant tubular glands. Intestinal differentiation may be present. 